\title{
Wind tunnel measurement of aerodynamic characteristics of trains passing each other on a simply supported box girder bridge
}

\author{
Xiaozhen $\mathrm{Li}^{1} \cdot$ Yiling $\operatorname{Tan}^{1} \cdot$ Xiaowei Qiu ${ }^{1} \cdot$ Zhenhua Gong$^{1} \cdot$ Ming Wang1
}

Received: 20 October 2020/Revised: 5 January 2021 / Accepted: 6 January 2021/Published online: 26 February 2021

(C) The Author(s) 2021

\begin{abstract}
The aerodynamic performance of high-speed trains passing each other was investigated on a simply supported box girder bridge, with a span of $32 \mathrm{~m}$, under crosswinds. The bridge and train models, modeled at a geometric scale ratio of 1:30, were used to test the aerodynamic forces of the train, with the help of a designed moving test rig in the XNJD-3 wind tunnel. The effects of wind speed, train speed, and yaw angle on the aerodynamic coefficients of the train were analyzed. The static and moving model tests were compared to demonstrate how the movement of the train influences its aerodynamic characteristics. The results show that the sheltering effect introduced by trains passing each other can cause a sudden change in force on the leeward train, which is further influenced by the wind and running speeds. Detailed analyses related to the effect of wind and train speeds on the aerodynamic coefficients were conducted. The relationship between the change in aerodynamic coefficients and yaw angle was finally described by a series of proposed fitting formulas.
\end{abstract}

Keywords Aerodynamic coefficient - Two trains passing each other - Simply supported box girder bridge $\cdot$ Wind tunnel

Xiaowei Qiu

qxw542106512@126.com

$\triangle$ Ming Wang

Charming_1989@my.swjtu.edu.cn

1 School of Civil Engineering, Southwest Jiaotong University, Chengdu 610031, China

\section{Introduction}

Recently, the rapid development of high-speed trains has attracted much research, focusing on running comfort and operational stability, where the dynamic response of trains is mainly affected by track irregularity excitation [1,2], wind load [3-5], and bridge vibration, for the vehiclebridge coupling system [6]. Prior research has also found that the action of the wind load is a major performanceaffecting factor [7, 8]. The measurement of aerodynamic characteristics provides an important reference for the dynamic response of vehicles under wind loading.

Generally speaking, studies related to the aerodynamic characteristics of trains under crosswind usually adopt a full-scale test, wind tunnel test, and computational fluid dynamic (CFD) simulation. For full-scale tests, Tian and Liang [9] successfully conducted pressure measurements of a train during its intersection on a Guangzhou Shenzhen high-speed railway and discussed the relationship between the amplitude of the pressure wave and the train running speed. Xiong and Liang [10] tested the surface pressure of CRH2 with two trains passing each other on the Jiaoji Railway, where the space between the two lines is $4.4 \mathrm{~m}$. A maximum pressure of $1195 \mathrm{~Pa}$ was recorded on the car body surface, with the train running at $250 \mathrm{~km} / \mathrm{h}$. Hideyuki et al. [11] discussed the dynamic performance of maglev train intersections through a field measurement method and proposed a measure to improve the running comfort. Although the field measurements can be reliably used to study the aerodynamic changes of two-train intersections, the high measurement cost, low efficiency, and unstable wind environment usually limit its application.

The numerical simulation method is currently adopted to study the unsteady flow field of trains. Hwang et al. [12] adopted CFD to study the influence of the head shape and 
length of the train on its aerodynamic forces, before and after the tunnel. Liu and Tian [13] measured the air pressure change on the train as it moves through the tunnel, the air pressure inside the tunnel, and the micro-pressure wave at the tunnel entrance. Seong et al. [14] used the comparative method of numerical simulation and real train testing to analyze the pressure wave of a high-speed train entering a tunnel. Khayrullina et al. [15] used CFD numerical simulation software and a large eddy simulation method to study the influence of passing passenger and freight trains on the wind field of a platform in a tunnel. Zampieri et al. [16] studied a numerical device that can reproduce the flow field around a full-scale high-speed train through a real train test and CFD numerical simulation.

Compared to the full-scale test and numerical simulation, the wind tunnel test is still widely used to measure the aerodynamic characteristics of trains under complex wind environments [17]. Baker et al. [18] measured the aerodynamic characteristics of the Mark 3 train in the UK and compared it with the wind tunnel test results of a 1:30 scale train model. The results of the full-scale and wind tunnel experiments demonstrated good agreement with each other and also illustrated the need to consider local roughness in the wind tunnel test. Cheli et al. [19] tested the aerodynamic effect of the ETR500 train running on different infrastructures through a wind tunnel test and found that the rolling moment coefficient was affected by the acceleration associated with the infrastructure scenarios. Several researchers also conducted relevant studies on the aerodynamic characteristics of trains passing each other. $\mathrm{Li}$ et al. $[20,21]$ adopted the wind tunnel test to measure the aerodynamic forces on two trains meeting each other on a suspension bridge. The results showed that the effect of a sudden change in the wind load on highway traffic vehicles was more obvious than that that of rail transit vehicles, and that the aerodynamic coefficients of vehicles on the leeward side decreased sharply while the vehicle on the windward side was relatively flat during the intersection. Qiu et al. [22] conducted a wind tunnel test on the aerodynamic forces of the moving train model for trains passing on a steel truss bridge under crosswind. The results showed that the aerodynamic coefficients of the moving vehicles on the leeward side exhibited a sudden change when the two vehicles met and the aerodynamic coefficients were mainly affected by the train speed.
In addition to the conventional excitations affecting the dynamic response of the train, the common two-train intersection during operation also affects their dynamic performance. Raghunathan et al. [23], Tian [24], and Sun et al. [25] studied the intersection effect of trains running inside a tunnel and found that the intersection movement introduced an obvious suction force between two trains and, consequently, fluctuating forces. In addition, the intersection effect of trains passing on a truss bridge was also investigated by Qiu et al. [22], revealing that the bridge structure formed a shielding effect on the train on the leeward side. However, research related to the intersection effect of trains running on a wildly distributed simply supported box girder bridge is limited, where the intersection effect of trains may be more obvious compared to trains running on a truss bridge, due to the strong wind environment.

This study aims to investigate the aerodynamic characteristics of trains passing each other on a simply supported box girder bridge under crosswind using a wind tunnel test. The bridge and $\mathrm{CRH} 3$ train system were modeled at a ratio of 1:30 in the wind tunnel test. The test was conducted using a moving test rig. A comparison between the static and dynamic train model tests was conducted. The influences of train speed, wind speed, and yaw angle on the aerodynamic coefficient of the train are discussed.

\section{Wind tunnel test}

\subsection{Description of the moving train wind tunnel test system}

The test was conducted in the XNJD-3 wind tunnel, measured at $36.0 \mathrm{~m} \times 22.5 \mathrm{~m} \times 4.5 \mathrm{~m}$. Considering the size of the test objects, a moving test system was adopted to test the aerodynamic forces of the train model. As shown in Fig. 1, the moving train wind tunnel test system comprises a bridge model, train model, and driving system. The train model is moved via a servomotor, synchronous belt, and sliders. The speed of the servo motor rotor is controlled by setting the target speed and running distance of the servo system. The servo motor rotor drives the train model through the synchronous belt to make the train model pass through the test section at a certain constant speed. Based on the principle that the inertial force in the acceleration

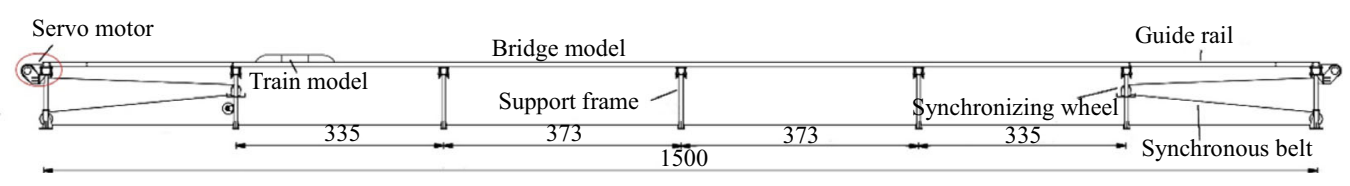

Fig. 1 General schematic diagram of the test system (unit: $\mathrm{cm}$ ) 


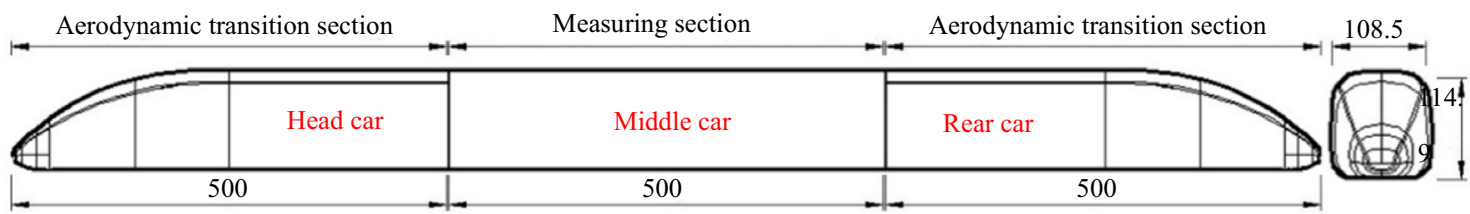

Fig. 2 Train model (unit: $\mathrm{mm}$ )

and deceleration sections does not exceed the range of the balance, and the test time of the uniform speed section is extended as far as possible, the time in the acceleration and deceleration sections is set to $0.5 \mathrm{~s}$. The detailed arrangement of each part can be found in $\mathrm{Li}$ et al. [17].

\subsection{Train and bridge models}

Considering the influence of the wind tunnel blockage ratio and the aerodynamic interaction between the train and bridge, the test model was manufactured at a 1:30 geometric scale to ensure the model simulation and test are as accurate as possible. As seen in Fig. 2, the train is simplified as a three-section train model, comprising the head, middle, and rear cars. The middle car is chosen as the test car, while the head and rear cars are chosen as the aerodynamic transition sections to ensure the aerodynamic stability of the force measuring car. The test train model simplifies the structure of the wheelset, bogie, and hemlines owing to their limited influence on the aerodynamic characteristics of the train under crosswind. The test mainly focuses on studying the change in aerodynamic forces of the train at the leeward side caused by the intersection effect.

The bridge model is designed according to the $32 \mathrm{~m}$ simply supported concrete box girder pre-stressed in the post-tensioning method for a $350 \mathrm{~km} / \mathrm{h}$ high-speed railway. The bridge model is separated from the guide rail and train model. The separation of the track and bridge in the bridge

(a)

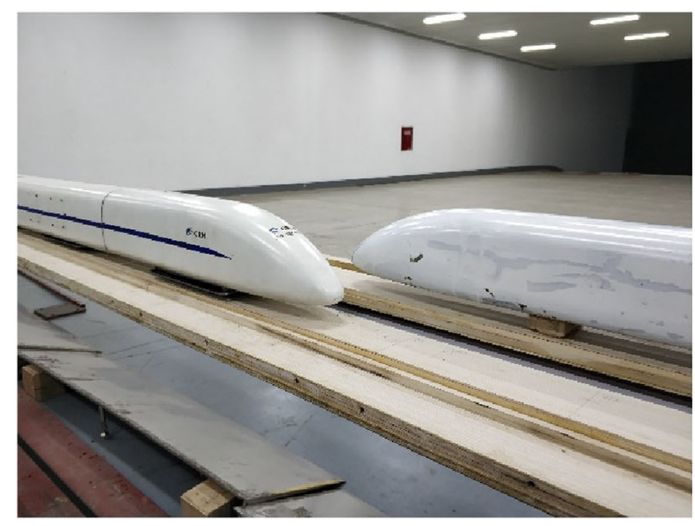

installation layout can not only avoid the adverse impact of the model bridge on the smoothness of the guide rail but also achieve a convenient layout for different bridge types. In this study, the truss bridge model of Wang et al. [26] is replaced by the box girder model in Fig. 3 to study the aerodynamic characteristics of a two-train intersection on a simply supported box girder bridge.

The wind tunnel test is performed with the static train model at the windward side and the moving train model at the leeward side. During the test, a wireless six-component balance was installed inside the middle car of the moving train model to test the aerodynamic forces during the motion of the train model. The parameters of the wireless balance are listed in Table 1. The accuracy of the balance was sufficient to meet the test requirements. As shown in Fig. $4, F_{x}, F_{y}$, and $F_{z}$ are the forces in the $x, y$, and $z$ directions relative to the coordinate system. $F_{x}$ and $F_{y}$ represent the lift force, side force, respectively. $M_{x}, M_{y}$, and $M_{z}$ are the moments in the $x, y$, and $z$ directions relative to the coordinate system, respectively; $M_{z}$ represents the rolling moment.

Wind tunnel experiments are commonly performed for moving train models. The actual wind velocity relative to the moving train of $V_{\text {res }}$ and the relative wind angle (yaw angle $\beta$ ) is the sum of the train speed and incoming wind vectors owing to the movement of the trains. As shown in Fig. 4, $U$ represents the mean incoming wind velocity, $V_{\mathrm{T}}$ is the train speed, and $\alpha$ is the angle between the crosswind

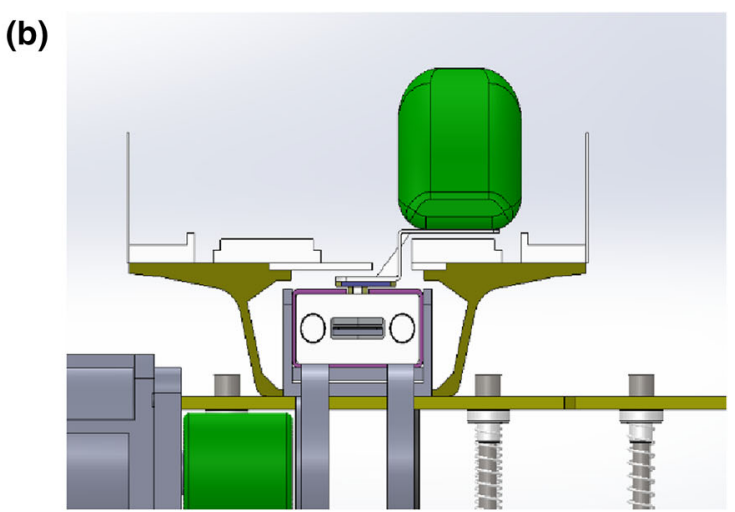

Fig. 3 Bridge model and arrangement: a the wind tunnel test of a two-train intersection; $\mathbf{b}$ details of the side view of the bridge model 
Table 1 Transducer specifications

\begin{tabular}{lllllll}
\hline Parameters & $F_{x}(\mathrm{~N})$ & $F_{y}(\mathrm{~N})$ & $F_{z}(\mathrm{~N})$ & $M_{x}(\mathrm{~N} \cdot \mathrm{m})$ & $M_{y}(\mathrm{~N} \cdot \mathrm{m})$ & $M_{z}(\mathrm{~N} \cdot \mathrm{m})$ \\
\hline Range & $-20-20$ & $-20-20$ & $-60-60$ & $-1-1$ & $-1-1$ \\
Resolution ratio & $1 / 200$ & $1 / 200$ & $1 / 100$ & $1 / 8000$ & $1 / 8000$ \\
\hline
\end{tabular}

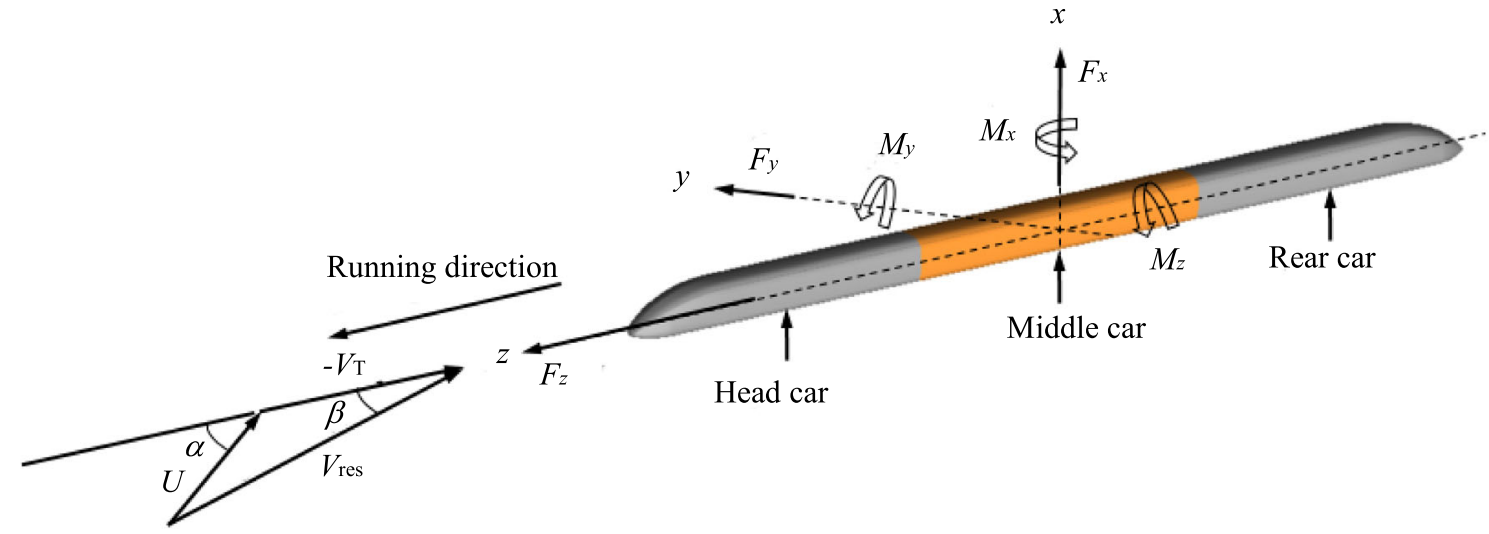

Fig. 4 Speed vector and aerodynamic forces

and direction of travel. The mean side force, lift force, and rolling moment coefficients can be defined as follows:

$C_{\mathrm{L}}=F_{x} /\left(\frac{1}{2} \rho U^{2} B L\right)$,

$C_{\mathrm{S}}=F_{y} /\left(\frac{1}{2} \rho U^{2} H L\right)$,

$C_{\mathrm{R}}=M_{z} /\left(\frac{1}{2} \rho U^{2} B^{2} L\right)$,

where $C_{\mathrm{L}}$ is the lift force coefficient (the straight-up direction is chosen to be positive), $C_{\mathrm{S}}$ is the side force coefficient (the incoming wind direction is chosen to be positive), $C_{\mathrm{R}}$ is the rolling moment coefficient (the train running direction is chosen to be positive), $\rho$ is the air density, $H$ is the height of the mobile train model, $L$ is the length of the mobile train model, and $B$ is the width of the mobile train model.

\subsection{Test cases}

The results show that the aerodynamic characteristics of the train are most unfavorable under the action of a crosswind [27], i.e., $\alpha=90^{\circ}$. The direction of the incoming wind is set to be perpendicular to the axis of the bridge for this test. The wind speed in the test was continuously adjustable. This test was conducted in a uniform flow field. The sampling frequency of the measurement was set to $1024 \mathrm{~Hz}$. To reduce the error of the dynamic test, the test was repeated three times for each test case, taking the average value as the final result. The test cases are listed in Table 2.

To more intuitively describe the influence of the static train on the aerodynamic parameters of the test train during the intersection process, the abscissa representing the time history in the following figures is converted into the forward distance of the train according to the corresponding speed. As shown in Fig. 5, the central position of the static train is taken as the original point of the relative coordinate. Based on the location of the head car, 25 static measuringpoints (T1-T25) are arranged and the distance between adjacent measuring points is $0.15 \mathrm{~m}$.

\section{Aerodynamic coefficients for trains passing each other}

A wind speed of $0 \mathrm{~m} / \mathrm{s}$ and train speed of $0 \mathrm{~m} / \mathrm{s}$ were chosen as benchmark test cases to adjust the wireless balance to zero. The measured signal will include obvious fluctuations that need to be filtered according to the interference signal characteristics owing to the inevitable interference signals, such as train vibration, sliding block dynamic vibration, rail irregularity, and inertial force caused by the changing train speed. In order to reduce the interference of the test system on the aerodynamic force of the moving train as much as possible, the original time history data is processed through a low-pass filter at $7 \mathrm{~Hz}$.

In Fig. 6, taking the train speed of $1 \mathrm{~m} / \mathrm{s}$ and wind speed of $10 \mathrm{~m} / \mathrm{s}$ as examples, it can be seen that the interference 
Table 2 Test cases

\begin{tabular}{llll}
\hline Train speed $(\mathrm{m} / \mathrm{s})$ & Wind speed $(\mathrm{m} / \mathrm{s})$ & $\alpha\left(^{\circ}\right)$ & Track position of moving train \\
\hline $1-7$ & $5-10$ & 90 & Leeward side \\
\hline
\end{tabular}

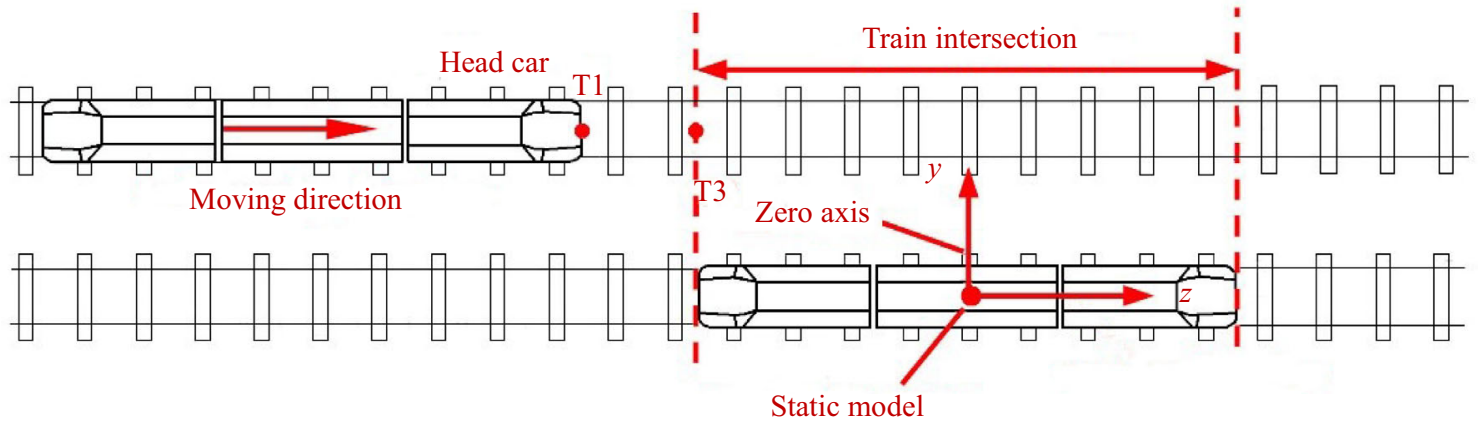

Fig. 5 Measuring point locations

signal affecting the aerodynamic coefficients of the train is significantly reduced after signal processing. The wind forces of the train on the leeward side are found to suddenly decrease when the leeward train runs into the section of the windward static train model, which should be due to the shielding effect of the windward train model on wind flow around the leeward train. As the distance between the moving and windward train increases, the wind forces suddenly increase. During the entire intersection process between the two trains, the train on the leeward side experiences a sudden change in force in different directions, which introduces a significant change in the dynamic response of the train.

\subsection{Comparison between static and moving model tests}

To compare and analyze the difference in the aerodynamic coefficients of the train in the moving and static states, when the test train passes through the intersection region, a wind speed of $8 \mathrm{~m} / \mathrm{s}$ was chosen to compare the aerodynamic coefficients of the train model running at different speeds. The time histories of the aerodynamic coefficients are shown in Fig. 7.

During the period of two-trains intersecting, $C_{\mathrm{L}}$ of the static model is smaller than that of the moving model. This is because of the difference in flow speeds at the top and bottom of the train between the moving and static models. The negative pressure at the top of the moving train is much larger than that of the static train. $C_{\mathrm{S}}$ and $C_{\mathrm{R}}$ of the static model are larger than those of the moving model because of the change in the two-side flow separated from the head car. The blocked flow of two trains during the intersection process introduces a suction force, causing a negative side force and moment ( $\mathrm{Li}$ et al. [20, 21]. The increase in train speed also increases the negative side force and moment.

\subsection{The effect of train speed on the shielding effect}

The test cases of $V_{\mathrm{T}}=2,4$, and $6 \mathrm{~m} / \mathrm{s}$, with $U=8 \mathrm{~m} / \mathrm{s}$, were chosen to investigate the effect of the train speed on the aerodynamic coefficients of moving trains. The aerodynamic coefficients of the leeward train for different speeds are shown in Fig. 8.

In Fig. 8, the change in train speed shows a significant influence on the change in the aerodynamic coefficients of the train. Here, the intersection affected area of the train is defined as the maximum value of the initial peak position of the coefficient, between the position of the final wave peaks. Through observation, with the increase in the train speed, the intersection affected area of $C_{\mathrm{L}}, C_{\mathrm{S}}$ and $C_{\mathrm{R}}$ is amplified. The discovery by Hwang et al. [12] also reveals a similar change in the intersection affected area for different train speeds.

\subsection{The effect of crosswind speed on aerodynamic coefficients}

Wind speeds of 6,8 , and $10 \mathrm{~m} / \mathrm{s}$, with $V_{\mathrm{T}}=1 \mathrm{~m} / \mathrm{s}$ were selected to study the influence of wind speed on the aerodynamic coefficient of moving trains. The results are shown in Fig. 9.

The change in wind speed has an insignificant influence on the sudden change in the aerodynamic coefficients of the train. The process of the intersection in Fig. 9 shows that the different wind speeds have little effect on the intersection affected area. Taking $C_{\mathrm{S}}$ as an example, the 

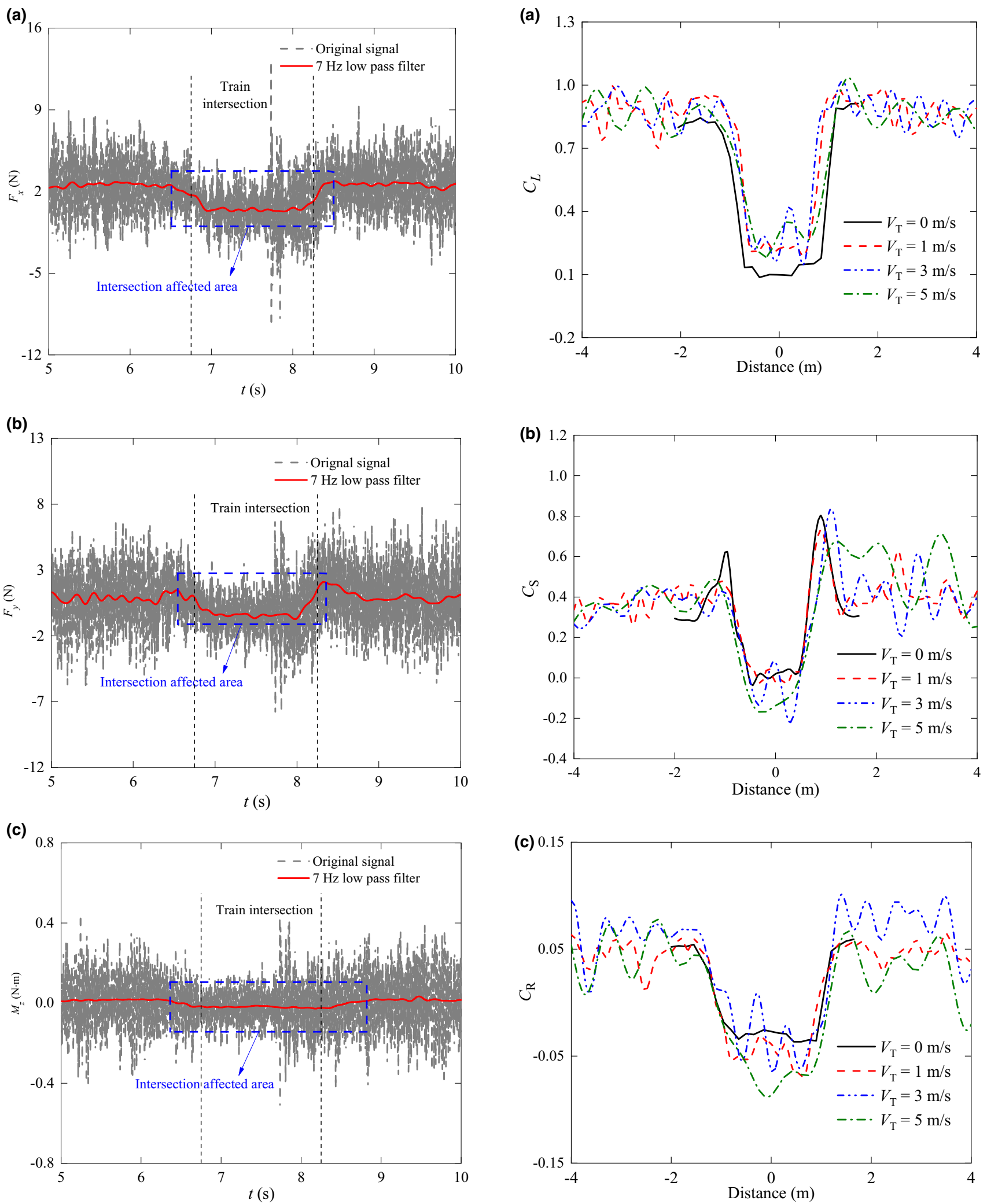

Fig. 6 Data processing $\left(U=10 \mathrm{~m} / \mathrm{s}, V_{\mathrm{T}}=1 \mathrm{~m} / \mathrm{s}\right)$ : a lift force, $\mathbf{b}$ side force, and c Rolling moment

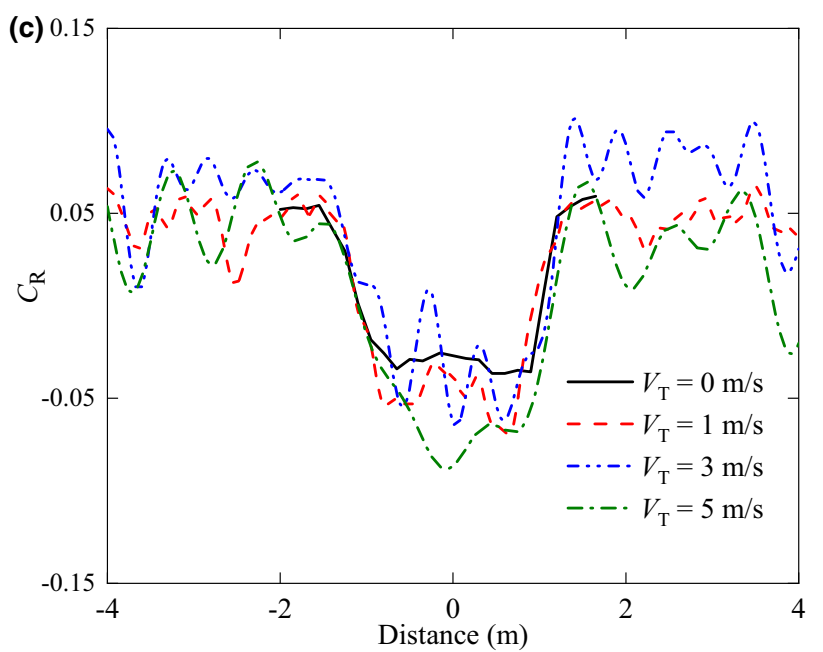

Fig. 7 The static and dynamic comparison of train aerodynamic coefficients $(U=8 \mathrm{~m} / \mathrm{s})$ : a lift force, coefficient, b side force coefficient, and $\mathbf{c}$ rolling moment coefficient 
(a)

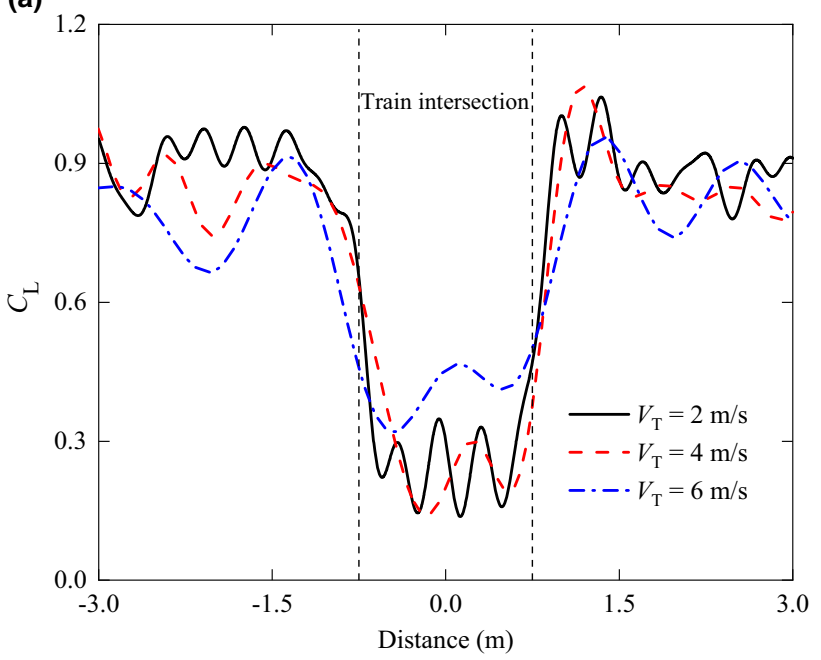

(b)

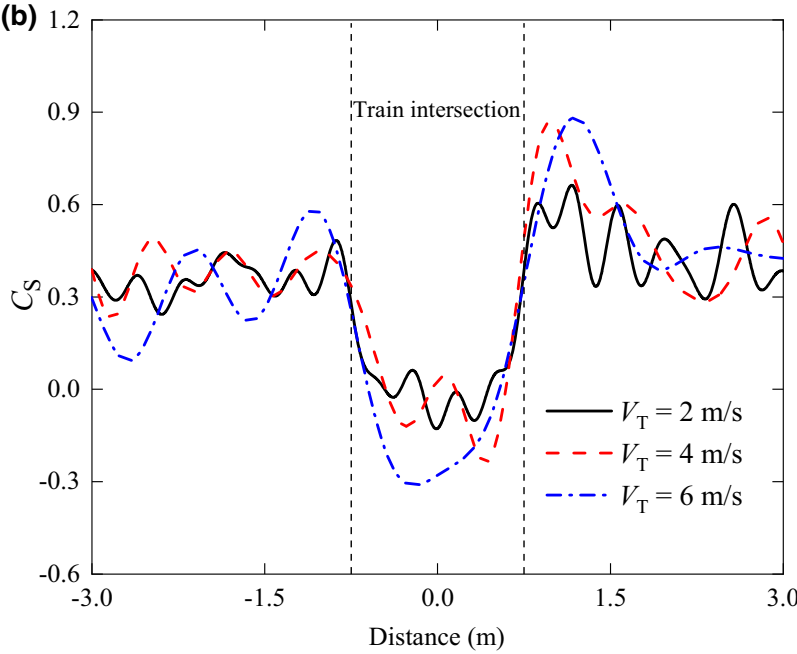

(c)

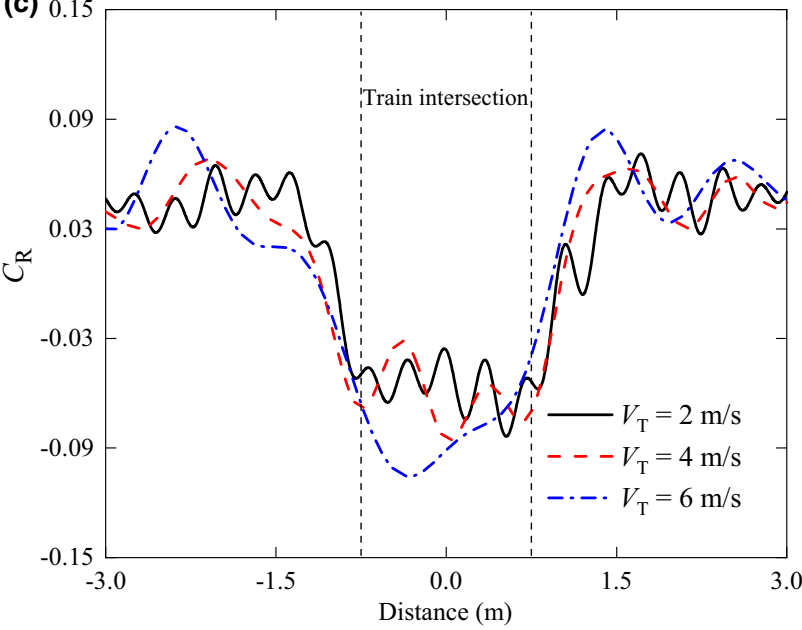

Fig. 8 The aerodynamic coefficients of the leeward train with different train speeds $(U=8 \mathrm{~m} / \mathrm{s})$ : a lift force coefficient, b side force coefficient, and $\mathbf{c}$ rolling moment coefficient intersection affected area under different wind speeds is approximately $2 \mathrm{~m}$. In contrast to $C_{\mathrm{L}}$ and $C_{\mathrm{R}}$, two obvious peaks at the locations near the still train are found for $C_{\mathrm{S}}$. The high pressure between two trains with their noses moving toward each other introduces the above peaks in $C_{\mathrm{S}}$ [12].

\subsection{Relationship between the sudden change of force and aerodynamic coefficients with yaw angle}

To investigate the synthesized influence of wind and train speed on the sudden change of the three-component aerodynamic coefficients during the intersection process, the test cases, including wind speeds from $5-10 \mathrm{~m} / \mathrm{s}$ and train speeds from 1-7 m/s, are shown in Figs. 10 and 11, defined by the aerodynamic forces and coefficients, respectively. Taking the side force as an example, the sudden change of the side force $\Delta F_{y}$ is the difference between the averaged side force of two stable sections, i.e., where the middle car locates behind the static train model on the windward side and in the front of the intersection. The calculation method of other sudden changes is the same as above.

Figure 10 shows the change in the lift force $\Delta F_{x}$, the change in side force $\Delta F_{y}$, and the change in the rolling moment $\Delta M_{z}$ with the error bars, with different wind and train speeds. The change in the three-component aerodynamic forces increases with the increase in wind speed. The increase in train speed can increase $\Delta F_{y}$ and $\Delta M_{z}$ but decrease $\Delta F_{x}$.

The aerodynamic coefficients with error bars for different wind and train speeds are shown in Fig. 11. The change in lift coefficient $\Delta C_{\mathrm{L}}$ increases with the increase in wind speed but decreases with the increase in train speed, while the change in the side coefficient $\Delta C_{\mathrm{S}}$ decreases with the increase in wind speed but increases with train speed. The change in the rolling coefficient $\Delta C_{\mathrm{R}}$ increases with the increase in wind speed and train speed and the trend is extremely flat. When the wind speed reaches $8 \mathrm{~m} / \mathrm{s}$, the change in the three-component aerodynamic coefficients tends to be stable. The effect of the Reynolds number can be used to explain the above changes; the Reynolds number, $R e=\rho U H / \eta$ (where $\eta$ is the air viscosity coefficient), is close to $6 \times 10^{4}$ when the wind speed is greater than $7 \mathrm{~m} / \mathrm{s}$. A similar value of Reynolds number can be found in Baker [28], where the aerodynamic coefficients of a $1 / 50$ scale model of an advanced passenger train were tested.

From Fig. 11, we can see that the three-component aerodynamic coefficients are affected by both the train and wind speed. To explore their commonality, a graph of the three-component aerodynamic coefficients with error bars with yaw angle is shown in Fig. 12. $\Delta C_{\mathrm{L}}$ increases with an increase in the yaw angle and $\Delta C_{\mathrm{S}}$ decreases with the 

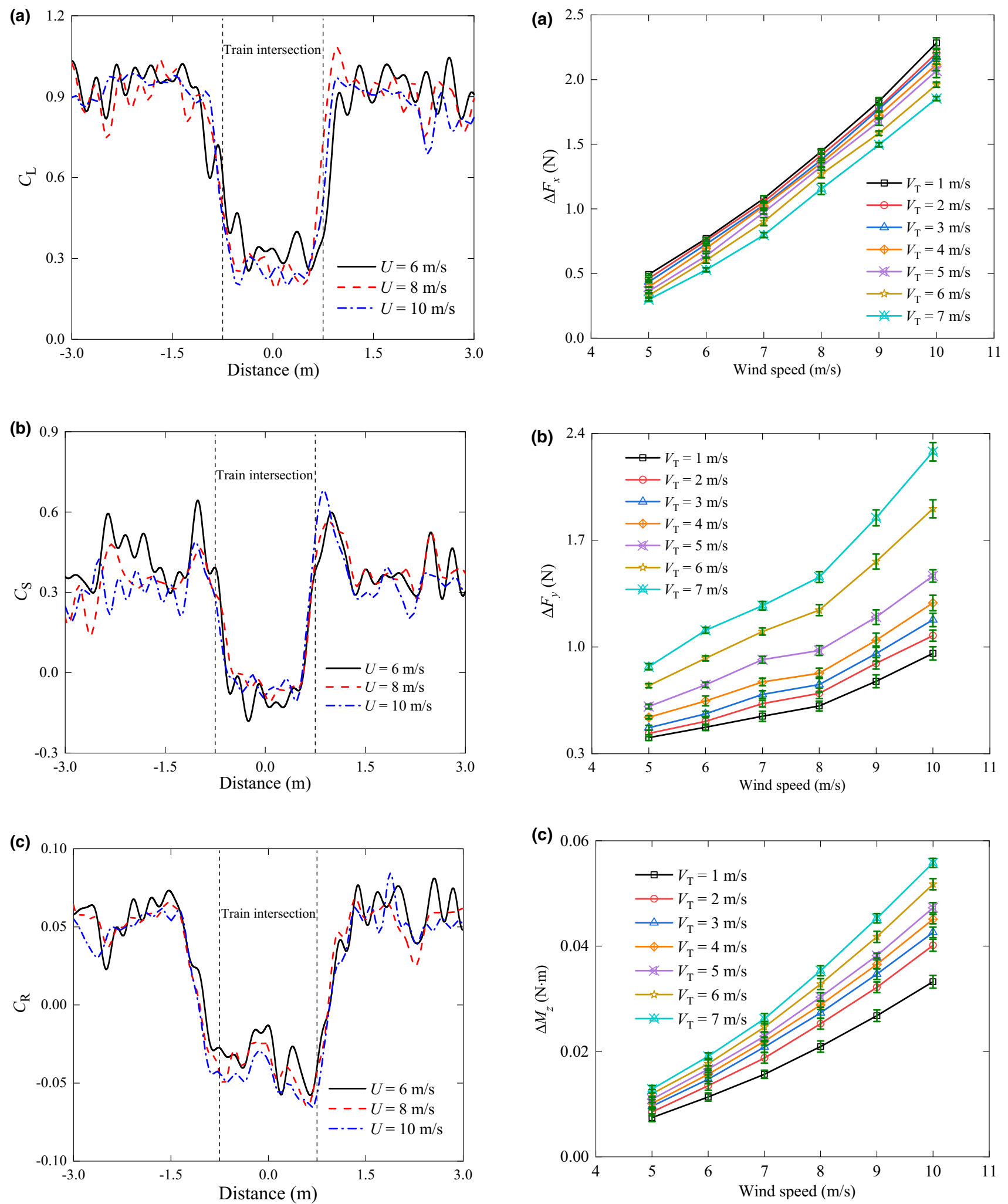

Fig. 9 The aerodynamic coefficients of the leeward train with different wind speeds $\left(V_{\mathrm{T}}=1 \mathrm{~m} / \mathrm{s}\right)$ : a lift force coefficient, b side force coefficient, and $\mathbf{c}$ rolling moment coefficient

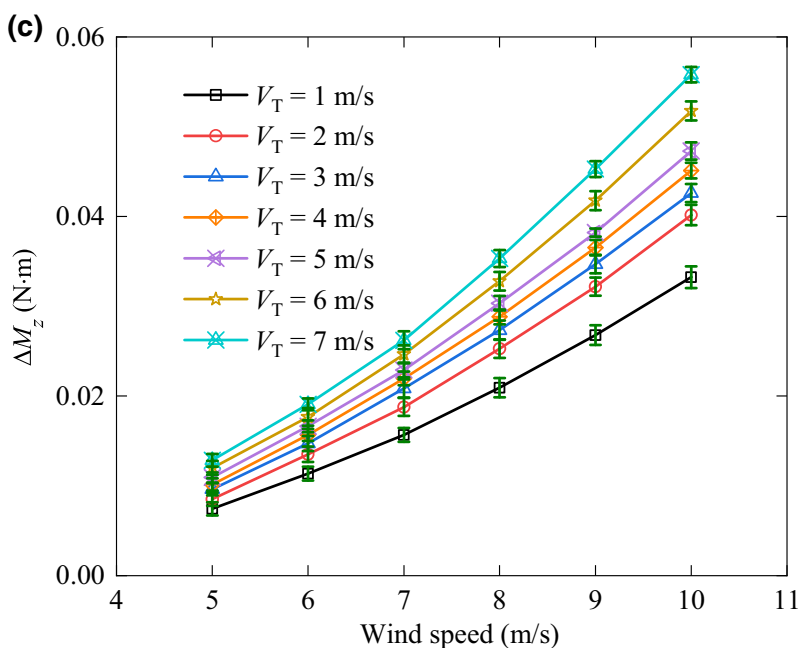

Fig. 10 The sudden change in train aerodynamic forces with different wind and train speeds $\left(U=5-10 \mathrm{~m} / \mathrm{s}\right.$, and $\left.V_{\mathrm{T}}=1-7 \mathrm{~m} / \mathrm{s}\right)$ : a sudden change in lift force, $\mathbf{b}$ sudden change in side force, and c sudden change in rolling moment 

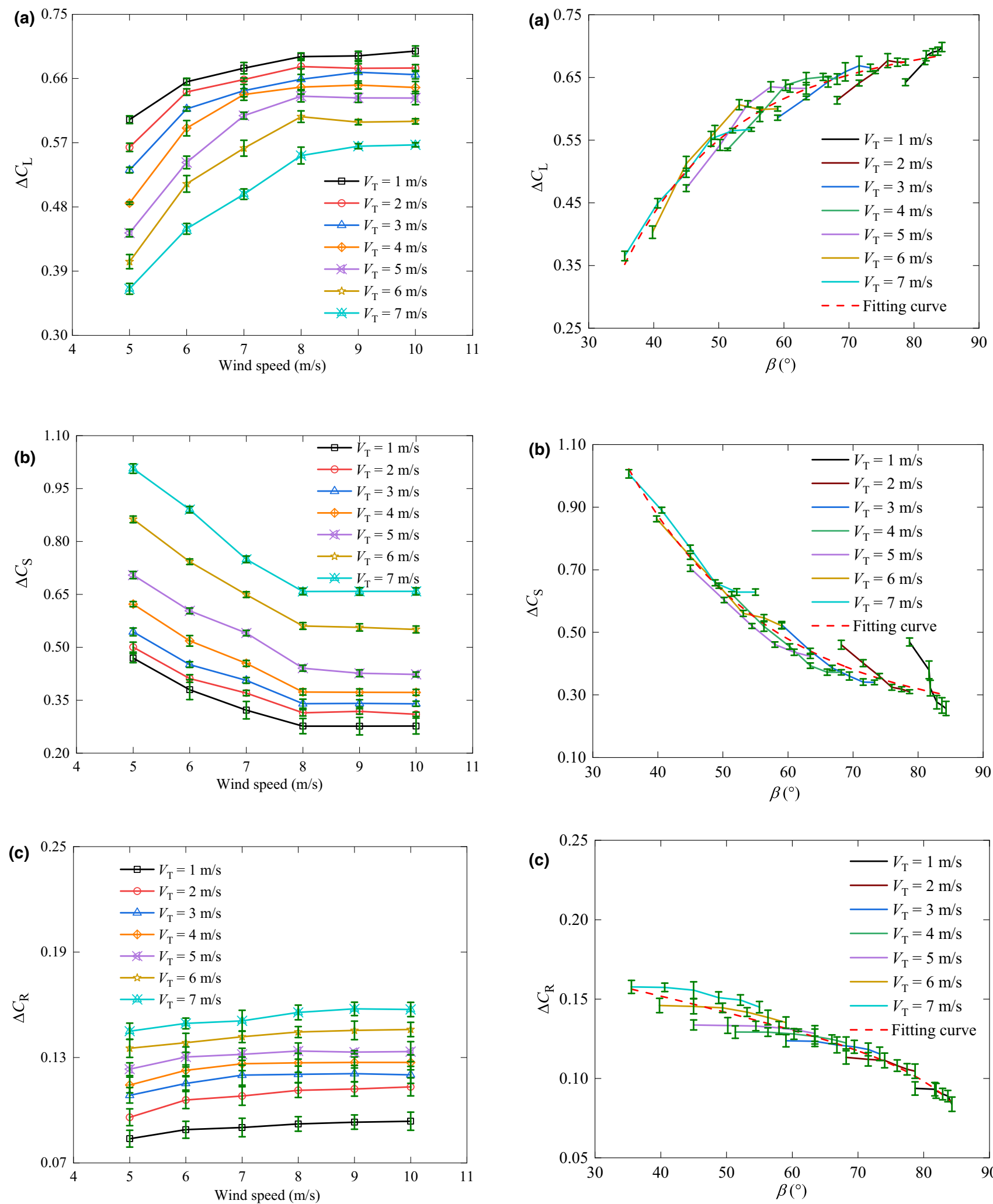

Fig. 11 The sudden change in train aerodynamic coefficients with different wind and train speeds $\left(U=5-10 \mathrm{~m} / \mathrm{s}\right.$ and $\left.V_{\mathrm{T}}=1-7 \mathrm{~m} / \mathrm{s}\right)$ : a sudden change in lift force coefficient, $\mathbf{b}$ sudden change in side force coefficient, and $\mathbf{c}$ sudden change in rolling moment coefficient

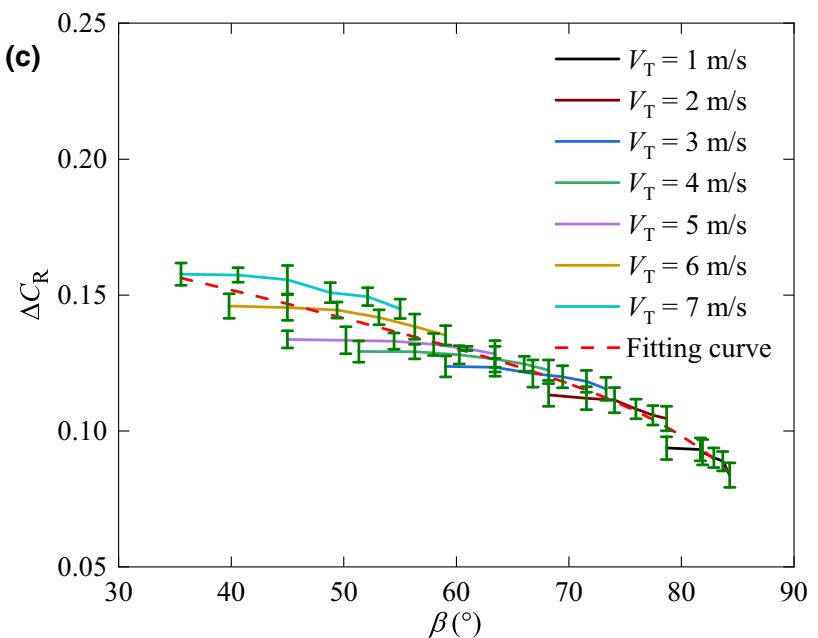

Fig. 12 Relationship between the sudden change in train aerodynamic coefficients and yaw angle $\left(U=5-10 \mathrm{~m} / \mathrm{s}\right.$ and $\left.V_{\mathrm{T}}=1-7 \mathrm{~m} / \mathrm{s}\right)$ : a sudden change in lift force coefficient, $\mathbf{b}$ sudden change in side force coefficient, and $\mathbf{c}$ sudden change in rolling moment coefficient 
Table 3 Fitting curve formulas

\begin{tabular}{ll}
\hline Coefficient & Formula \\
\hline$\Delta C_{\mathrm{L}}$ & $y=-2.36461+1.53145\left(1-\mathrm{e}^{-x / 16.44945}\right)+1.53145\left(1-\mathrm{e}^{-x / 16.44945}\right)$ \\
$\Delta C_{\mathrm{S}}$ & $y=4.2802-2.03459\left(1-\mathrm{e}^{-x / 22.0424}\right)-2.0342\left(1-\mathrm{e}^{-x / 22.02464}\right)$ \\
$\Delta C_{\mathrm{R}}$ & $y=0.39768-0.17763 \mathrm{e}^{(x+39.6007) / 245.07037}-5.05354 \times 10^{-10} \mathrm{e}^{(x+39.6007) / 7.11375}$ \\
\hline
\end{tabular}

decrease in yaw angle. $\Delta C_{\mathrm{R}}$ decreases with a decrease in yaw angle, but its trend is relatively gentle. Compared with the trend shown in Fig. $12, \Delta C_{\mathrm{L}}$ and $\Delta C_{\mathrm{S}}$ are more affected by the wind speed.

To facilitate practical engineering applications and conveniently determine $\Delta C_{\mathrm{L}}, \Delta C_{\mathrm{S}}$ and $\Delta C_{\mathrm{R}}$ through the yaw angle in the future, the fitting curves in Fig. 12 and formulas for the change in three-component aerodynamic coefficients with yaw angle were obtained via curve-fitting (Table 3).

\section{Conclusions}

In this study, the aerodynamic characteristics of two passing trains were investigated in a wind tunnel test. The following conclusions can be drawn:

(1) Compared with the aerodynamic characteristics of the static and dynamic train models, $C_{\mathrm{L}}$ of the static model is smaller than that of the moving model, and $C_{\mathrm{S}}$ and $C_{\mathrm{R}}$ of the static model are larger than those of the moving model, respectively.

(2) The length of the intersection affected area is greatly affected by the train speed while the wind speed has little effect on it.

(3) For the aerodynamic forces, $\Delta F_{x}, \Delta F_{y}$, and $\Delta M_{Z}$ increase with increasing wind speed. For the aerodynamic coefficients, $\Delta C_{\mathrm{L}}$ increases with yaw angle and $\Delta C_{\mathrm{S}}$ and $\Delta C_{\mathrm{R}}$ decrease with yaw angle, but for $\Delta C_{\mathrm{R}}$ the trend is relatively flat. $\Delta C_{\mathrm{S}}$ and $\Delta C_{\mathrm{L}}$ are more affected by wind speed. When the wind speed reaches $8 \mathrm{~m} / \mathrm{s}$ and the Reynolds number is close to $6 \times 10^{4}$, the aerodynamic coefficients will not be affected by the Reynolds number.

(4) To facilitate determining the yaw angle, for engineering applications, the fitting curves and certain formulas of the three-component aerodynamic coefficient changing with the yaw angle were obtained through curve fitting.

Acknowledgements This work was financially supported by the National Natural Science Foundation of China (U1434205, 51708645).
Open Access This article is licensed under a Creative Commons Attribution 4.0 International License, which permits use, sharing, adaptation, distribution and reproduction in any medium or format, as long as you give appropriate credit to the original author(s) and the source, provide a link to the Creative Commons licence, and indicate if changes were made. The images or other third party material in this article are included in the article's Creative Commons licence, unless indicated otherwise in a credit line to the material. If material is not included in the article's Creative Commons licence and your intended use is not permitted by statutory regulation or exceeds the permitted use, you will need to obtain permission directly from the copyright holder. To view a copy of this licence, visit http://creativecommons. org/licenses/by/4.0/.

\section{References}

1. Lei S, Ge Y, Li Q (2020) Effect and its mechanism of spatial coherence of track irregularity on dynamic responses of railway vehicles. Mech Syst Signal Process 145:106957

2. Xu L, Zhai W-M (2018) The vehicle-track stochastic model considering joint effects of cross-winds and track random irregularities. J Vib Eng 31(1):39-48 (in Chinese)

3. Dorigatti F, Sterling M, Rocchi D, Belloli M, Quinn AD, Baker CJ, Ozkan E (2012) Wind tunnel measurements of crosswind loads on high sided vehicles over long span bridges. J Wind Eng Ind Aerodyn 107-108:214-224

4. Zou S-M, He X-H, Wang H-F, Tang L-B, Peng T-W (2020) Wind tunnel experiment on aerodynamic characteristics of high-speed train-bridge system under crosswind. J Traffic Transp Eng 20(1):132-139 (in Chinese)

5. Zhang Y, Li J, Chen Z, Xu X (2019) Dynamic analysis of metro vehicle traveling on a high-pier viaduct under crosswind in Chongqing. Wind Struct Int J 29(5):299-312

6. Hou K, Fei Z, Hua B, Wang S (2019) Safety and stability of highspeed train moving on multi-span simply supported girder bridges in ground subsidence area. IOP Conf Ser Earth Environ Sci 218:012113

7. Wang M, Chen X, Li X, Yan N, Wang Y (2020) A frequency domain analysis framework for assessing overturning risk of high-speed trains under crosswind. J Wind Eng Ind Aerodyn 202:104196

8. Yan NJ (2018) Study on wind field characteristics, aerodynamic load and overturning risk of moving train under transverse wind. Dissertation, Southwest Jiaotong University

9. Tian H, Liang X (1998) Test research on crossing air pressure pulse of quasi high-speed train. J China Railw Soc 20(2):37-42 (in Chinese)

10. Xiong X, Liang $X$ (2009) Analysis of air pressure pulses in meeting of CRH2 EMU trains. J China Railw Soc 31(6):15-20 (in Chinese)

11. Hideyuki T, Ren DQ, Zhou XQ (2004) The vehicle dynamics characteristics of a magnetic levitation train passing another train running in opposite direction. J Foreign Roll Stock 41:30-33 
12. Hwang J, Yoon TS, Lee D, Lee S (2001) Numerical study of unsteady flowfield around high speed trains passing by each other. JSME Int J Ser B 44(3):451-464

13. Liu T, Tian H (2008) Comparison analysis of the full-scale train tests for trains with different shapes passing tunnel. China Railw Sci 29(1):51-55 (in Chinese)

14. Seong WN, Hyeok BK, Su HY (2012) Characteristics method analysis of wind pressure of train running in tunnel. J J Kor Soc Railw 15(5):436-441

15. Khayrullina A, Blocken B, Janssen W, Straathof J (2015) CFD simulation of train aerodynamics: train-induced wind conditions at an underground railroad passenger platform. J Wind Eng Ind Aerodyn 139:100-110

16. Zampieri A, Rocchi D, Schito P, Somaschini C (2020) Numerical-experimental analysis of the slipstream produced by a high speed train. J Wind Eng Ind Aerodyn 196:104022

17. Li XZ, Wang M, Xiao J, Zou Q-Y, Liu D-J (2018) Experimental study on aerodynamic characteristics of high-speed train on a truss bridge: a moving model test. J Wind Eng Ind Aerodyn 179:26-38

18. Baker CJ, Jones J, Lopez-Calleja F, Munday J (2004) Measurements of the crosswind forces on trains. J Wind Eng Ind Aerodyn 92(7-8):547-563

19. Cheli F, Corradi R, Rocchi D, Tomasini G, Maestrini E (2010) Wind tunnel tests on train scale models to investigate the effect of infrastructure scenario. J Wind Eng Ind Aerodyn 98(6-7):353-362
20. Li Y-L, Hu P, Zhang M-J, Qiang S-Z (2011) Effect of sudden change of vehicle wind loads in wind-vehicle-bridge system by wind tunnel test. Acta Aerodyn Sin 29(5):353-362 (in Chinese)

21. Li Y, Xiang H, Zang Y, Qiang S (2011) Coupling vibration of wind-vehicle-bridge system for the process of two trains passing each other. China Civ Eng J 44(12):73-78 (in Chinese)

22. Qiu X-W, Li X-Z, Sha H-Q, Xiao J, Wang M (2018) Wind tunnel measurement of aerodynamic characteristics of trains passing each other on truss bridge. China J Highw Transp 31(7):548-566 (in Chinese)

23. Raghunathan RS, Kim H-D, Setoguchi T (2002) Aerodynamics of high-speed railway train. Prog Aerosp Sci 38(6-7):469-514

24. Tian H (2007) Train Aerodynamics. China Railway Press, Beijing (in Chinese)

25. Sun Z, Zhang Y, Guo D, Yang G, Liu Y (2014) Research on running stability of $\mathrm{CRH} 3$ high speed trains passing by each other. Eng Appl Comput Fluid Mech 8(1):140-157

26. Wang M, Li X-Z, Xiao J, Zou Q-Y, Sha H-Q (2018) An experimental analysis of the aerodynamic characteristics of a highspeed train on a bridge under crosswinds. J Wind Eng Ind Aerodyn 177:92-100

27. He X, Zou Y, Zhou J, Li H (2015) Effect of wind environment parameters on aerodynamic characteristics and critical wind velocity of vehicle operation. J China Railw Soc 37(5):15-20 (in Chinese)

28. Baker CJ (1986) Train aerodynamic forces and moments from moving model experiments. J Wind Eng Ind Aerodyn 24(3):227-251 